(1]

'Fondazione IRCCS Ca' Granda Ospedale Maggiore Policlinico, Cystic Fibrosis Centre, Milan, Italy. 'Fondazione IRCCS Ca' Granda Ospedale Maggiore Policlinico, U.O.C. Direzione delle Professioni Sanitarie, Milan, Italy.

${ }^{3}$ Università degli Studi di Milano, Dept of Clinical Sciences and Community Health, Milan, Italy.

\title{
Respiratory physiotherapy education in Italy: per aspera ad astra
}

Cite as: Gambazza S. Respiratory physiotherapy education in Italy: per aspera ad astra. Breathe 2018; 14 : 250-252.

\section{Training overview}

At the start of my career, following 3 years of undergraduate education in physiotherapy, it was crystal clear that I was more inclined to the respiratory field rather than musculoskeletal or neurological practice. At that time, after six enthusiastic months spent at Lacor Hospital (Gulu, Uganda) writing my graduation thesis, my remaining options were a 2-year Master's level degree (MSc), introduced in Italy in late 2004, randomly following some educational courses offered by the only Italian association of physiotherapists dealing with respiratory disease (Associazione Riabilitatori dell'Insufficienza Respiratoria; ARIR) or, eventually, deepening my understanding and, therefore, management of respiratory diseases through the available 1-year postgraduate track at the University of Milan (Milan, Italy). The MSc was about some nonspecific aspects of physiotherapy, such as health management, economics and general research issues, while the postgraduate course, established in 2006 and currently celebrating its 13th edition, was offering 60 university training credits (Crediti Formativi Universitari; CFU), equivalent to approximately 1500 hours of work (lessons, individual study, preparation for the exam, research work, etc.). Taking into consideration the fact that a bachelor's degree in physiotherapy is obtained after 180 CFU and that the average amount of hours dedicated to the respiratory area corresponds, more or less, to less than $10 \%$ of the total CFU, it was not difficult for me to opt for the 1-year postgraduate track.

\section{A brief reflection on physiotherapy}

Soon after, I experienced the American approach. As a member of the ARIR board of directors, I was sent to visit respiratory therapists in Boston (MA, USA). You may already know that respiratory therapy and physiotherapy (or physical therapy) are two very separate jobs in the USA. I was very impressed looking at these two professionals taking care of one patient at the same time: the first dealing with airways and the latter with bone and muscle issues, thus understanding the value of having advanced skills in one clinical area.

The American practice reinforced the importance of following evidence-based practice instead of adhering to the because-the-boss-said-so approach. I believe that the physiotherapists' relationship with evidence-based practice was not enthusiastic at the very beginning and actually has not yet reached its peak. I would say that observation and verification influenced physiotherapy as a skill-based rather than researchbased profession, thus shifting the time in which physiotherapists realised that the real drive of their practice was evidence and not attitude or sartorial elegance. This was not the only barrier, of course. For example, up until 1999 the Italian Ministry of Health used to identify physiotherapists as auxiliary staff (auxilium is the Latin word for help), and one of the consequences could have been that only physicians were allowed to generate and appraise scientific evidence, informing physiotherapists' afterwards (the author's unpublished data). It is hilarious that in a recent conference held by some 


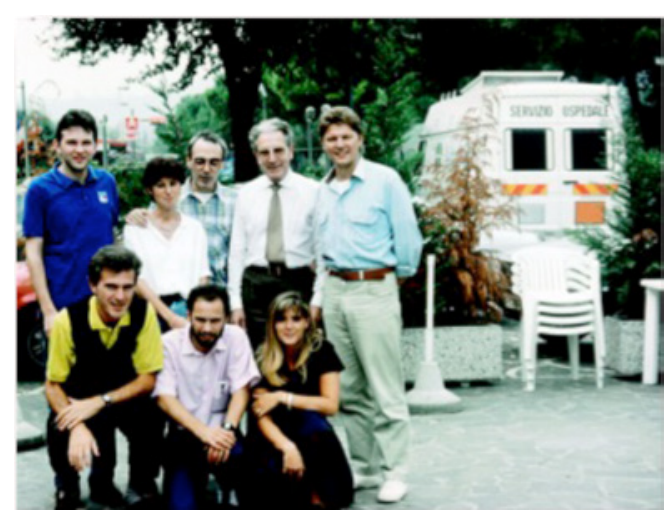

Figure 1 Giovanni Oliva and Prof. Italo Brambilla (top row, first and second from right) pictured together with Monica Bassi and Alessandro Aina (bottom row, first and second from right) and other young physiotherapists and pulmonologists from Niguarda Ca' Granda hospital (Milan, Italy). In the late 1980s, the farsighted Prof. Brambilla founded the first outpatient service in Milan for people receiving oxygen therapy and began to rehabilitate respiratory patients. The picture was taken in Sirmione, Italy, where they were on a short trip with patients. Giovanni Oliva was the first to campaign for the establishment of a respiratory physiotherapy specialisation in Italy.

physiatrists here in Italy, the same schizophrenic approach was there again. Indeed, one could have listened to one physiatrist talking about assessment and patient evaluation and to one physiotherapist explaining what to do. This introduces the theme of professional autonomy. As in other European countries, Italian patients need a referral from a physician to consult a physiotherapist within the public system; however, professional autonomy was first ratified by Italian laws in 1994 [1] and then in 2000 [2]. Today physiotherapists administer autonomously, or in collaboration with other health professionals prevention, treatment and rehabilitation interventions. The Italian association of physiotherapists (Associazione Italiana Fisioterapisti; AIFI) and the World Confederation for Physical Therapy have extensively illustrated how autonomy implies independence whenever physiotherapists assess patients and choose the best treatment following a medical diagnosis and, paraphrasing Kant, I add that autonomy should not be influenced by feelings, personal interests or fears.

At the end of my visit to the USA, I realised that respiratory therapy staff in the USA also had time and funds for research, and dedicated people to run bench research and clinical studies. To the best of my knowledge, this is unusual in many European countries, also considering that physiotherapy education is not uniform across Europe [3]. For example, according to the national collective agreement for physiotherapists, time to be dedicated to research equals zero. Generally, this means that those who have skills in designing and running trials or who want to invest in research to answer relevant clinical questions receive help from colleagues to lighten their workload, at least in general public hospitals, where lack of time is perceived as another barrier.

If physiotherapists are not involved in research, how can we expect students during their training to receive any mentoring on this matter thus moving the profession forward? Indeed the picture of Italian academia is quite alarming. Yet in 2014 the scientific level of Italian physiotherapists qualifying for a university career was not considered up to standard [4] by the commission of non-physiotherapists nominated by the Italian Ministry of Education, University and Research, with backgrounds and specialisations that differed from the field they were asked to evaluate. It was estimated that the Italian population of physiotherapists was 65000 , of whom seven are now listed in the "Sciences of nursing, rehabilitation and neuropsychiatric techniques" section area of university faculty members, resulting in a prevalence of $0.01 \%$ [5]. None of these physiotherapists deals with respiratory diseases. To this, one must add a number of physiotherapists employed as a contract professor, who are unquantifiable at the moment. Therefore, the likelihood of not having access to academic funding to sponsor high-quality research is very high, as is the chance of having students who receive education from non-physiotherapists in Italian universities, and this is the worst scenario.

Nevertheless, there are currently more than 360 physiotherapists involved in scientific publications, with an increasing number of publications per years, as reported by VerCELLI et al. [5]. Assuming that educational level will vary with time, one could say that higher education will bring new chances to draw a different academic scenario. To date, the amount of physiotherapists holding a Doctoral degree (PhD) is about $0.05 \%$ : access to $\mathrm{PhD}$ programmes was only possible after 2008 , when the first physiotherapists had obtained an MSc degree.

\section{New challenges}

Eloquence, attitude and funding are a good basis but are not enough for running good research, and the only way to explore the reality in which we work is the ability to translate phenomena into numbers, and then using mathematics and statistics try to meet patients' needs. During my undergraduate education I received only 0.5 CFU in statistics, nearly 17 hours of formulas, useless to any clinical purpose. And so I found a university professional programme in medical statistics, which gave me a basic knowledge, enough to realise how influencing numbers can be. I moved from Florence to Milan, under the supervision of another mentor who gave me the opportunity to put into practice what I learned during the last course. Later, I selected a MSc in Cognitive Sciences and Decisional Processes, the final door to a PhD. Working mainly with 
patients with cystic fibrosis since 2009 , I decided to deepen the knowledge behind the effects of exercise on some brain functions, mixing previous research skills with new insights derived from the cognitive neuroscience curriculum.

At present, I have quit the clinical routine and the insane habit of doing research during my spare time, as well as the uncomfortable feeling of being a physiotherapist in a public general hospital without any formal recognition of the acquired specific competencies. Indeed, right after my MSc graduation I applied for a PhD programme in Public Health Sciences, in which I am currently enrolled.

There is lack of physiotherapists in universities who can be champions of physiotherapy education. Given the absence of professors in physiotherapy, no one looks after the education of physiotherapy students. Up to this point, mentorship and its role in advancing the physiotherapy profession must be mainly attributed to scientific associations. AIFI and ARIR, to name the ones dearest to me, are doing the hardest job in educating, mentoring and motivating young physiotherapists. My first mentor was one of the past directors of the ARIR journal, and thanks to her I valued the profession and its respiratory specialisation. After my first mentor, the people who influenced my choices all belong to scientific groups. I believe many other Italian colleagues share the same feeling. For example, as far as respiratory physiotherapy education is concerned, ARIR was able to offer more than 120 continuous medical educational credits during 2017 (the credit limit for physiotherapy equals 150 continuous medical educational credits in a 3-year period), representing de facto the major source of update in respiratory physiotherapy. Its educational role rose in the late 1980s [6], when a multidisciplinary team of physiotherapists and pulmonologists under the guidance of Prof. Italo Brambilla developed more and more interest around respiratory physiotherapy and pulmonary rehabilitation, especially for patients receiving oxygen therapy. Thanks to the postgraduate track on respiratory physiotherapy and pulmonary rehabilitation, more than 200 physiotherapists are giving continuity to this field, which is requested in public and private health facilities, despite the fact that the specialisation is not legally recognised or adequately funded.

While we are waiting for a Copernican revolution in Italian universities, July 2018 will be remembered by Italian physiotherapists as the time when we obtained a regulatory body [7], after a political crusade that has lasted 30 years. To quote the Associazione Italiana Fisioterapisti, "we will be more, more recognised, more cohesive and therefore stronger".

\section{Conclusions}

Am I a respiratory physiotherapist? Well, according to the Italian Ministry of Health, I do not even exist. Basically, I hold an academic title not formally recognised by any public or private hospital. However, I am a respiratory physiotherapist and patients, scientific associations and industries do acknowledge our skills. As it happens in biology, I wish that our social shape as respiratory physiotherapists could be determined even by new functions within the health system, academia and society. One day, I expect people to stop asking why I need a PhD to do a massage.

\section{Conflict of interest}

S. Gambazza reports personal fees from Vertex Pharmaceuticals, outside the submitted work.

\section{References}

1. Ministero Della Sanita'. DECRETO 14 settembre 1994, n. 741. www.gazzettaufficiale.it/eli/id/1995/01/09/095G0001/sg Date last accessed: July 25, 2018.

2. Parlamento Italiano. Legge 10 agosto 2000 , n. 251. Disciplina delle professioni sanitarie infermieristiche, tecniche, della riabilitazione, della prevenzione nonchè della professione ostetrica. www.camera.it/parlam/leggi/00251I.htm Date last updated: September 6, 2000. Date last accessed: June 28, 2018.

3. Troosters T, Pitta F, Oberwaldner B, et al. Development of a syllabus for postgraduate respiratory physiotherapy education the respiratory physiotherapy HERMES project. Eur Respir J 2015; 45: 1221-1223.
4. Gatti R, Paci M, Vercelli S, et al. Has the Italian academia missed an opportunity? Phys Ther 2014: 1358-1360.

5. Vercelli S, Ravizzotti E, Paci M. Are they publishing? A descriptive cross-sectional profile and bibliometric analysis of the journal publication productivity of Italian physiotherapists. Arch Physiother 2018; 8: 1.

6. Lazzeri M, D’Abrosca F. Lo stato della Riabilitazione Respiratoria in Italia. Il punto di vista del Fisioterapista. Rass di Patol dell'Apparato Respir 2016; 31: 1-5.

7. Ministero Della Sanita'. DECRETO 13 marzo 2018. www.gazzettaufficiale.it/eli/id/2018/04/03/18A02393/sg Date last accessed: June 28, 2018. 